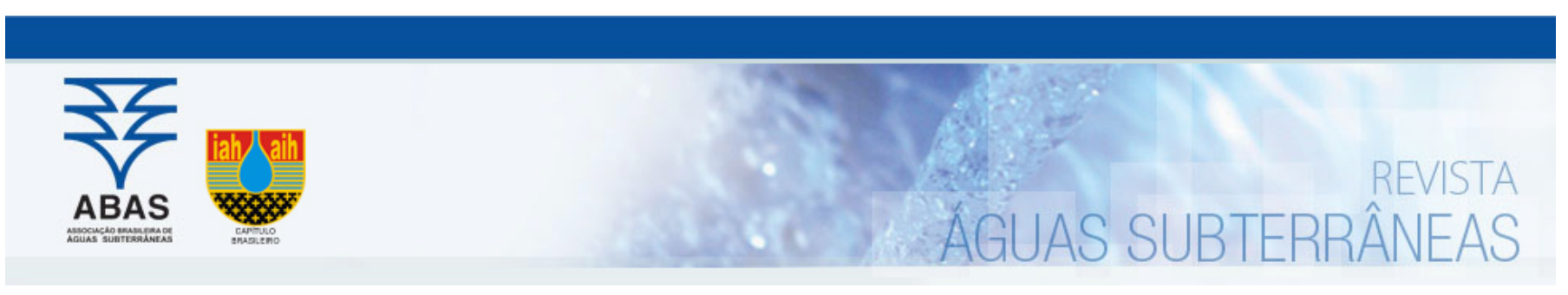

Artigos

\title{
Zona de Concentração de Cargas Contaminantes para Avaliação do Perigo de Contaminação da Água Subterrânea em Área Urbana
}

\author{
Contaminant Loading Concentration Zone to Assess the Groundwater Pollution \\ Hazard in Urban Area
}

\author{
Daniel Oliveira de Brito1; Pedro Antonio Roehe Reginato ${ }^{\circledR}$ \\ 1 Instituto de Pesquisas Hidráulicas - IPH/UFRGS, Porto Alegre, RS \\ $\triangle \underline{\text { danieloliveiradebrito@gmail.com, pedro.reginato@ufrgs.br }}$
}

Palvras-chave:

Água subterrânea.

Contaminação.

POSH.

Vulnerabilidade.

GOD.

\begin{abstract}
Resumo
O presente trabalho tem por objetivo propor a espacialização de cargas pontuais potencialmente contaminantes a partir de uma Zona de Concentração de Cargas Contaminantes (ZCCC) para a avaliação do perigo de contaminação da água subterrânea em área urbana. Aplicou-se a proposta na macrozona Cidade Radiocêntrica do Plano Diretor de Desenvolvimento Urbano e Ambiental de Porto Alegre. A ZCCC foi delimitada a partir da identificação das atividades potencialmente contaminantes e da aplicação de um raio de $100 \mathrm{~m}$ para as atividades comerciais e $200 \mathrm{~m}$ para os empreendimentos das demais naturezas. Dentro dessa zona, realizou-se a interpolação dos valores correspondentes ao índice POSH. Para avaliação do perigo de contaminação da água subterrânea, sobrepôs-se a ZCCC à vulnerabilidade natural do aquífero calculada pelo método GOD. Um total de 490 fontes potencialmente contaminantes foram identificadas e agrupadas em uma ZCCC que corresponde a 32\% da Cidade Radiocêntrica. 0 índice POSH interpolado dentro da ZCCC revelou uma boa representatividade das cargas contaminantes pontuais identificadas (75\% com índice elevado). A área de estudo apresenta uma vulnerabilidade majoritariamente média (98\%), e o perigo de contaminação varia de moderado (16\%) a alto (84\%) dentro da ZCCC. A espacialização proposta possibilitou uma análise da confluência das atividades potencialmente contaminantes e seu perigo de contaminação.
\end{abstract}

Abstract

This paper aims to propose a spatialization of potentially punctual contaminating loads in a Contaminant Loading Concentration Zone (CLCZ) for assess the hazard of groundwater contamination in urban areas. This propose was applied in macrozone Cidade Radiocêntrica of Porto Alegre's Urban and Environmental Development Master Plan. The CLCZ was delimited by identifying the potentially contaminating activities and applying a $100 \mathrm{~m}$ radius for the commercial activities and $200 \mathrm{~m}$ radius for other types of enterprises. Within this zone, the POSH index was interpolated. For assess the groundwater hazard, the CLCZ layer was overlapped on the vulnerability index layer calculated by GOD method. A total of 490 potentially contaminating activities were identified and grouped in a CLCZ which corresponds $32 \%$ of Cidade Radiocêntrica. The interpolated POSH index revealed a good representativeness of the identified potentially punctual contaminating loads ( $75 \%$ elevated). It was found that the study area has a mostly moderate vulnerability (98\%), and the groundwater pollution hazard ranges between moderate (16\%) and high (98\%) within the CLCZ. The spatialization propose allowed the evaluation of confluence of potentially contaminant activities and their pollution hazard.

DOI: http://dx.doi.org/10.14295/ras.v32i1.28882

\section{INTRODUÇÃO}

A degradação dos recursos hídricos subterrâneos pode acontecer direta ou indiretamente, tanto por causas naturais como antrópicas (BRASIL, 2007). Em relação à contaminação provocada pelo homem, sabe-se que o desenvolvimento urbano, agrícola e industrial é responsável pela descarga de resíduos e efluentes de forma pontual e não pontual (LIVINGSTONE et al, 1995). Foster et al (2006) classificam espacialmente as atividades potencialmente poluentes como difusas (as quais não geram plumas de contaminação claramente definidas - e.g. saneamento in situ e práticas agrícolas -) e pontuais (as que produzem plumas claramente definidas e concentradas).

As análises da vulnerabilidade da água subterrânea juntamente com informações sobre a localização de fontes potencialmente contaminantes constituem uma ferramenta para a avaliação do perigo de contaminação. Em um ambiente urbano, a ocupação do solo se 
dá de maneira descontínua e, desse modo, a distribuição das cargas contaminantes pontuais se sujeita a essa irregularidade espacial, fato que constitui óbice à avaliação do perigo de contaminação das águas subterrâneas.

Para avaliação da carga contaminante em área urbana, verifica-se no referencial teórico autores que se valem de uma análise individual de cada carga contaminante pontual (e.g. CUTRIM; CAMPOS, 2010), assim como aqueles que tratam o meio urbano como uma potencial fonte de contaminação difusa, como Meira et al (2014), que destacam a presença de postos de combustíveis e de agroindústrias como uma das justificativas para a consideração do perímetro urbano como fonte potencial de contaminação.

Pereira Junior et al (2015) propuseram empiricamente distintos raios de influência para as atividades de postos de combustíveis, núcleos granjeiros, aterro sanitário e poços tubulares profundos, considerando o usual não enquadramento desses às normas de projeto e construção de poços. Ainda assim, os autores atribuíram únicos valores à área urbana, destacando o precário esgotamento sanitário da região e a distribuição espacial dos postos de combustível.

Não se encontrou no referencial teórico proposta de integração e espacialização das diferentes cargas pontuais em uma área urbana. A avaliação especializada de cargas contaminantes se revela uma informação de maior utilidade para a gestão dos recursos hídricos subterrâneos em escala local, tendo em vista que delimitaria melhor essas situações, subsidiando um melhor direcionamento para gestão dessas áreas.

Este artigo tem por objetivo apresentar uma proposta de espacialização das cargas contaminantes pontuais a partir da geração de uma Zona de Concentração de Cargas Contaminantes (ZCCC), a qual considere a intrínseca descontinuidade do uso e ocupação do solo do meio urbano. Para exemplificação dessa proposta, será analisado o perigo de contaminação de uma região do município de Porto Alegre (RS) a partir da combinação da análise de vulnerabilidade natural da água subterrânea com a ZCCC que foi delimitada para a área de estudo.

\section{MATERIAIS E MÉTODO}

\section{1. Área escolhida para aplicação da proposta}

Selecionou-se para o presente artigo a macrozona Cidade Radiocêntrica do Plano Diretor de Desenvolvimento Urbano e Ambiental do município de Porto Alegre (PMPA, 2010), cuja localização é apresentada na Figura 1. Essa região possui $23,78 \mathrm{~km}^{2}$ e constitui a área mais estruturada do município, com a concentração de importantes avenidas, caracterizando-se por altas taxas de ocupação, revelando-se um local propício para a aplicação da proposta.

Figura 1 - Localização da área de estudo
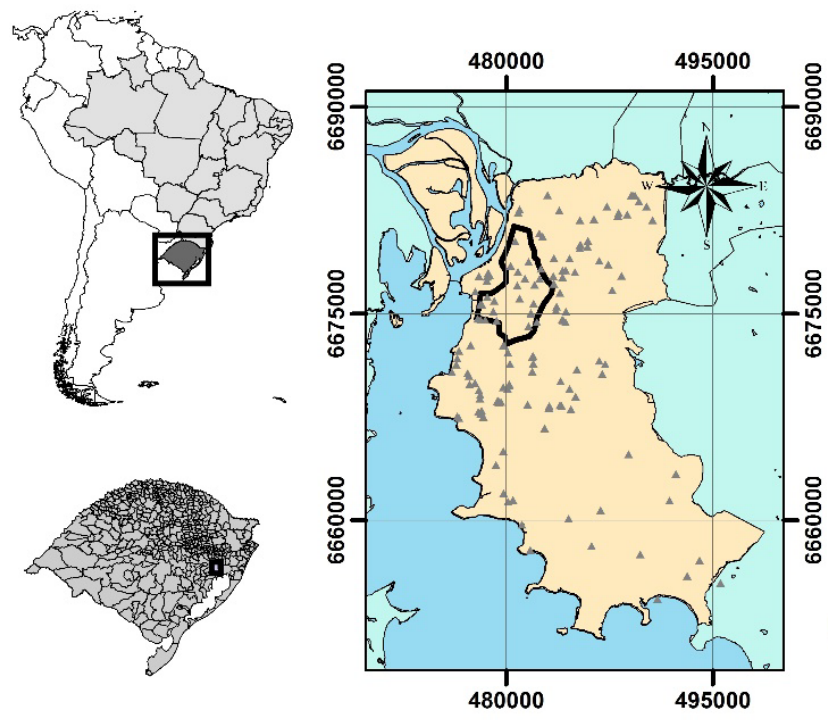

\section{Legenda}

\& Poços SIAGAS

$\square$ Cidade Radiocêntrica

Municípios RS

웅

$\square$ Porto Alegre

Datum: UTM SAD $6922 S$
Em Porto Alegre, a água subterrânea é utilizada para diferentes fins, sendo os principais relacionados com o uso em industrias, floriculturas e agricultura. Com base no Cadastro de Poços Tubulares do Departamento Municipal de Água e Esgoto do município (RODRIGUEZ et al, 2004), há o registro de cerca de 500 poços perfurados em Porto Alegre. No Sistema de Informações de Água Subterrânea (SIAGAS) desenvolvido pelo Serviço Geológico do Brasil (CPRM), estão cadastrados 143 poços, sendo que 30 apresentam uma insuficiência de dados e 01 se encontra fora dos limites de Porto Alegre. Dentre os 112 poços restantes, observa-se uma maior densidade naqueles localizados na área de estudo.

\subsection{Análise do perigo de contaminação da água subterrânea}

O perigo de contaminação consiste na probabilidade de um aquífero ter alguma substância química nociva inserida em função de alguma atividade antrópica. Foster et al (2006) propõem a avaliação desse perigo a partir da sobreposição dos dados de vulnerabilidade de um aquífero aos dados de carga contaminante de subsolo. Essa relação pode ser obtida a partir da multiplicação dos índices correspondentes à vulnerabilidade e às cargas contaminantes conforme a Equação 1, a qual expressa matematicamente a relação conceitualmente proposta por Foster et al (2006). Os diferentes intervalos do perigo calculado representam os perigos de contaminação da água subterrânea, que são apresentados na Tabela 1. 


$$
\text { PERIGO }=\text { VULN } \times \frac{\mathrm{CC}}{3}
$$

PERIGO: perigo de contaminação da água subterrânea [0 - 1];
VULN: índice de vulnerabilidade natural da água subterrânea [0 1]; CC: índice da carga contaminante [0 - 3].

Tabela 1 - Intervalos para avaliação do perigo de contaminação da água subterrânea

Perigo calculado

\begin{tabular}{cc}
\hline $0,00-0,04$ & Muito baixo \\
$0,04-0,10$ & Baixo \\
$0,10-0,25$ & Moderado \\
$0,25-0,50$ & Alto \\
$0,50-1,00$ & Extremo \\
\hline
\end{tabular}

\section{Classificação do perigo de contaminação da} água subterrânea

\subsection{Vulnerabilidade}

Para a avaliação da vulnerabilidade natural do aquífero, foi utilizado o método GOD (FOSTER; HIRATA, 1988), o qual apresenta uma simplicidade conceitual e prática. Ressalta-se que a facilidade de emprego do método não implica em uma informação menos válida, tendo em vista que métodos muito complexos os quais englobam muitos parâmetros, como o DRASTIC (ALLER et al, 1987), podem acabar utilizando dados correlacionados e sobrepostos, o que gera índices vagos (STEMPVOORT et al, 1993; FOSTER et al, 2006). Além disso, verifica-se no referencial teórico a ampla utilização do método GOD (e.g. TAVARES et al, 2009; ALBUQUERQUE FILHO et al, 2010; MARTELLI, 2011; PINHEIRO et al, 2013; FERON; REGINATO, 2014).

O método GOD consiste no produto de três variáveis cujo valor varia de 0 a 1, correspondendo, respectivamente, de uma vulnerabilidade insignificante a extrema. Os índices utilizados são: grau de confinamento hidráulico da água subterrânea (varia de 0 , aquíferos confinados, a 1, não confinados), ocorrência de estratos de cobertura (onde ocorre a atenuação do contaminante) e profundidade até o lençol freático ou aquífero confinado (índice inversamente proporcional à profundidade). Os parâmetros para esses índices podem ser verificados em Foster et al (2006), os quais diferem em alguns aspectos dos descritos por Foster e Hirata (1988).

Para determinação dos parâmetros, foram analisados os perfis construtivos dos poços de captação de água subterrânea cadastrados no SIAGAS, os quais dispõem de informações sobre a construção, localização, formação geológica, dados hidrogeológicos e do nível estático, além de informações gerais como nome do poço, proprietário e uso da água.

Os perfis construtivos e geológicos foram analisados visando identificar o aquífero captado pelo poço, a ocorrência de camada confinante ou de cobertura (parâmetro G), a descrição dos estratos de cobertura (parâmetro 0) e a profundidade do nível estático da água ou do teto do aquífero confinado (parâmetro D). Nos poços onde havia a ocorrência de mais de um estrato de cobertura, estabeleceu-se um índice composto para o valor de 0 , correlacionando a espessura de cada camada com o respectivo índice atribuído pelo método. $O$ parâmetro $D$ foi avaliado de acordo com o nível do teto da camada confinante para aquíferos confinados e a partir do nível estático para aquíferos livres.

Os valores calculados pelo produto dos parâmetros foram inseridos no software ArcGIS 10.2 e gerou-se uma superfície para o índice GOD através de interpolação pelo método Inverse Distance Weighting (IDW).

\subsection{Cadastro das cargas contaminantes e delimitação da Zona de Concentração das Cargas Contaminantes (ZCCC)}

Para o cadastro das cargas contaminantes, foi utilizado o método POSH (pollutant origin, surchage hydraulically), o qual se baseia na origem do poluente e sua sobrecarga hidráulica gerando três níveis de potencial contaminante: reduzido, moderado e elevado. Para as fontes pontuais, o método POSH propõe a seguinte classificação: oficinas mecânicas possuem índice 3 (elevado), postos de abastecimento índice 2 (moderado), cemitérios índice 1 (reduzido) e áreas industriais índice variável de acordo com o tipo da indústria (FOSTER et al, 2006).

Ressalta-se que este artigo se restringirá às fontes de contaminação pontuais. Em relação às fontes de contaminação difusa, Foster et al (2006) indicam as soluções de saneamento in situ e as práticas agrícolas. Em Porto Alegre, os efluentes das soluções individuais são lançados diretamente nas redes de drenagem pluviais ou sanitárias mais próximas do ponto de lançamento (DMAE, 2015) e, além disso, não se verifica a prática agrícola na Cidade Radiocêntrica.

A integração de áreas que representassem a distribuição das atividades potencialmente contaminantes foi feita a partir da aplicação de um buffer com valor de $100 \mathrm{~m}$ nos layers de postos de abastecimento e oficinas mecânicas, e um raio de $200 \mathrm{~m}$ para cemitérios e indústrias. Os valores adotados foram baseados na norma NBR 15.515-1:2007 (ABNT, 2007), a qual determina, para avaliações preliminares de passivo ambiental em solo e água subterrânea, a identificação dos bens a serem protegidos dentro de raios mínimos de $100 \mathrm{~m}$ a partir de fonte potencial oriunda de atividades comerciais, e localizadas em raios mínimos de $200 \mathrm{~m}$ a partir de empreendimentos das demais naturezas. Dentro das áreas geradas, interpolou-se o índice atribuído segundo o método POSH a partir de cada 
ponto presente nela pelo método IDW, gerando uma superfície limitada por essa zona de concentração.

Para obtenção das fontes potencialmente contaminantes, foram identificados e mapeados os cemitérios da área de estudo a partir de imagens de satélite do Google Earth. Os empreendimentos industriais e comerciais foram identificados a partir de registros da Secretaria Municipal de Produção, Indústria e Comércio (SMIC), a qual disponibiliza em seu site os Alvarás Cadastrados com informações de razão social, endereço, CEP, bairro e atividade. Os empreendimentos selecionados no cadastro da SMIC foram mapeados utilizando-se o site BatchGeo e o software ArcGIS 10.2, gerando um mapa temático das fontes potenciais de contaminação.

\section{RESULTADOS E DISCUSSÃO}

\subsection{Caracterização hidrogeológica da área de estudo}

$\mathrm{Na}$ área de estudo, observa-se que 11 poços captam água de aquíferos fraturados (gnaisse e granito), enquanto que 02 poços captam água de sedimentos arenosos e 03 de granitos intemperizados ( $\mathrm{Fi}-$ gura 2). De acordo com o mapa de Sistemas Aquíferos do Plano Diretor de Mineração da Região Metropolitana de Porto Alegre (CPRM, 2006), a macrozona contempla as unidades hidrogeológicas Pinheiro Machado (g3) e Dom Feliciano (g2), as planícies fluviolacustres atuais e subatuais (b2), além dos depósitos de encosta encobrindo litologias pertencentes ao Escudo Sul-Rio-Grandense (j2). As unidades g3 e g2 são caracterizadas pela ocorrência de aquíferos fraturados, enquanto que as unidades b2 e j2 pela presença de porosos. Ainda assim, identificaram-se poços mistos.

Figura 2 - Mapa hidrogeológico

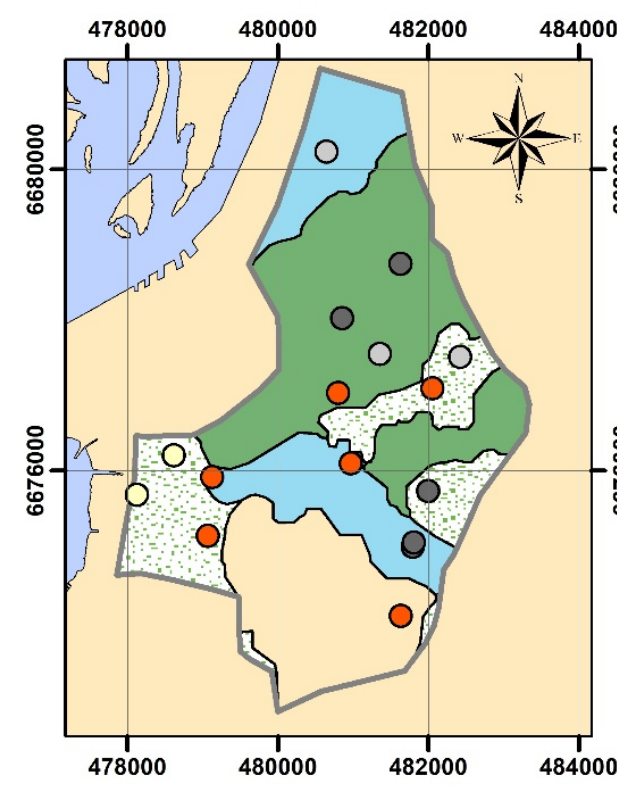

Legenda

Cidade Radiocêntrica
Entrada d'água dos poços
O Areia
$\bigcirc$ Gnaisse
$\bigcirc$ Granito
$\bigcirc$ Granito intemperizado

Unidades hidrogeológicas

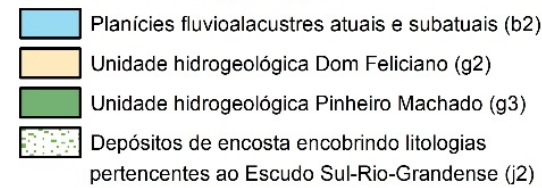

Datum: UTM SAD $6922 \mathrm{~S}$

\subsection{Vulnerabilidade}

Foram considerados outros 28 poços localizados na periferia da $\mathrm{Ci}$ dade Radiocêntrica além dos 16 inseridos na macrozona para a elaboração do índice de vulnerabilidade. Esses poços encontrados na circunferência da macrozona estão instalados nos mesmos Sistemas Aquíferos encontrados na Cidade Radiocêntrica. Assim, assumiu-se a semelhança nas características desses poços para elaboração do índice.

Os dados de identificação (código SIAGAS), coordenadas UTM fuso 22S, entrada d'água, nível estático, cota do terreno, litologia da zona filtrante dos poços, parâmetros para composição do índice GOD e a vulnerabilidade calculada dos 44 poços analisados são apresentados na Tabela 2. Deve-se levar em conta que uma limitação dessa análise consiste na qualidade da descrição dos perfis dos poços que constam no SIAGAS.

Em relação ao grau de confinamento (parâmetro G), percebe-se que a maior parte dos poços são apenas cobertos, ocorrendo somente 4 poços identificados como confinados em algum grau (4300000117, 4300000118, 4300018036 e 4300018066). Os valores variam de 0,2 (poço 4300000117 confinado por camada argilosa) até 0,9 (poço 430001052 coberto por pequena camada arenosa), sendo que a maioria dos poços (66\%) possui um valor de 0,6 ou 0,7 para esse parâmetro.

Quanto à ocorrência de estratos de cobertura (parâmetro 0), os poços apresentam valores que variam de 0,486 (para o poço 4300018120, o qual possui uma camada de areia argilosa, seguida por areia média, argila siltosa e tendo em sua base a ocorrência de rocha granítica) a 0,75 (para o poço 4300001439 , que possui uma camada de rochas intemperizadas em sua zona vadosa). A maior parte dos valores (77\%) se encontra no intervalo entre 0,6 e 0,7.

O teto da camada aquífera dos poços confinados varia entre 44,6 e $13 \mathrm{~m}$ de profundidade, correspondendo a um parâmetro $\mathrm{D}$ de 0,7 a 0,8 . Os poços não confinados apresentaram um nível estático que varia entre 112 e $0 \mathrm{~m}$ de profundidade, conferindo um índice $\mathrm{D}$ entre 0,6 e 0,9 .

O modelo gerado a partir da interpolação dos valores calculados é apresentado na Figura 3, conforme a classificação dada por Foster et al (2006) e, para uma melhor visualização das nuances da área de estudo, conforme as quebras naturais do raster gerado. Verificou-se que a Cidade Radiocêntrica possui em 98\% de sua área uma vulnerabilidade média (valores entre 0,3 e 0,5), com alguns locais ao norte e ao sul da macrozona com vulnerabilidade baixa (valores 
entre 0,1 e 0,3), correspondendo a $2 \%$ da área. A análise do histograma do raster calculado indica uma distribuição bimodal centrada nos valores de 0,33 e 0,39. Os menores valores ocorrem predominantemente na metade norte e em duas manchas no sul da macro zona, locais que podem ser caracterizados pela presença de poços com camadas argilosas e areno-argilosas nos estratos de cobertura (a destacar os poços 4300001446 e 4300000117 ao norte, e o 4300001052 ao sul), poços com uma maior profundidade no nível estático (4300018067, 430001801 e 4300018072 na porção centro-norte, 4300018076 ao sul da macrozona) e com maior profundidade do teto da camada confinante (4300018036 localizado ao sul da área de estudo). 0 maior grau de confinamento dos poços apresentou uma menor interseção espacial com os baixos valores de vulnerabilidade identificados, sendo possível estabelecer uma relação apenas na porção central (poço 4300018034), ao norte (4300000117 e 4300000118) e ao sul da Cidade Radiocêntrica (4300018036 e 4300018070).

Tabela 2 - Identificação dos poços tubulares utilizados e parâmetros do índice GOD

(continua)

\begin{tabular}{|c|c|c|c|c|c|c|c|c|c|c|}
\hline Poço & UTM E & UTM N & $\begin{array}{c}\text { Entrada } \\
\text { d'água (m) }\end{array}$ & $\begin{array}{l}\mathrm{NE} \\
(\mathrm{m})\end{array}$ & $\begin{array}{l}\mathrm{CT} \\
(\mathrm{m})\end{array}$ & G & 0 & D & GOD & $\begin{array}{l}\text { Litologia da zona } \\
\text { de captura }\end{array}$ \\
\hline 4300000117 & 482650 & 6680600 & 13 & 4,18 & 6 & 0,20 & 0,60 & 0,80 & 0,10 & SedAr \\
\hline 4300000118 & 480975 & 6682550 & 18 & 2,57 & 4 & 0,30 & 0,70 & 0,80 & 0,17 & ArCong \\
\hline 4300000124 & 478125 & 6675675 & 33 & 1 & 5 & 0,70 & 0,70 & 0,90 & 0,44 & $\operatorname{ArG}$ \\
\hline 4300001049 & 483614 & 6675216 & 11 & 2,98 & 19 & 0,70 & 0,65 & 0,90 & 0,41 & ArM \\
\hline 4300001052 & 477923 & 6674603 & 18 & 2,32 & 6 & 0,90 & 0,55 & 0,90 & 0,45 & SedAl \\
\hline 4300001432 & 484134 & 6674519 & 8,5 & 7,88 & 27 & 0,85 & 0,70 & 0,80 & 0,48 & GrIntemp \\
\hline 4300001438 & 482390 & 6680817 & 26 & 3,5 & 4 & 0,70 & 0,63 & 0,90 & 0,40 & $\mathrm{Gr}$ \\
\hline 4300001439 & 483474 & 6677166 & 21,4 & 19,8 & 80 & 0,80 & 0,75 & 0,80 & 0,48 & $\mathrm{Gr}$ \\
\hline 4300001440 & 480114 & 6672158 & 17 & 5,15 & 58 & 0,85 & 0,70 & 0,80 & 0,48 & Grlntemp \\
\hline 4300001444 & 482425 & 6677507 & 22 & 0,23 & 45 & 0,70 & 0,60 & 0,90 & 0,38 & GrAlt \\
\hline 4300001445 & 484313 & 6674378 & 15 & 9,53 & 27 & 0,70 & 0,53 & 0,80 & 0,30 & $\mathrm{Gr}$ \\
\hline 4300001446 & 480647 & 6680233 & 19 & 3,27 & 4 & 0,70 & 0,55 & 0,90 & 0,34 & GrAlt \\
\hline 4300001447 & 483406 & 6677700 & 15 & 9,55 & 74 & 0,80 & 0,62 & 0,80 & 0,40 & Grlntemp \\
\hline 4300001449 & 478620 & 6676200 & 19 & 2,31 & 7 & 0,80 & 0,66 & 0,90 & 0,47 & ArCong \\
\hline 4300016929 & 484089 & 6678118 & 51 & 3 & - & 0,60 & 0,59 & 0,90 & 0,32 & $\mathrm{Gr}$ \\
\hline 4300017157 & 478698 & 6677955 & 52 & 14,52 & - & 0,70 & 0,62 & 0,80 & 0,35 & $\mathrm{Gr}$ \\
\hline 4300017328 & 478590 & 6677670 & 108 & 72,91 & 1 & 0,70 & 0,70 & 0,60 & 0,29 & $\mathrm{Gr}$ \\
\hline 4300017331 & 478770 & 6677807 & 67 & 19,2 & 13 & 0,70 & 0,70 & 0,80 & 0,39 & $\mathrm{Gr}$ \\
\hline 4300018034 & 480970 & 6676092 & 39 & 9 & - & 0,60 & 0,68 & 0,80 & 0,33 & $\mathrm{Gr}$ \\
\hline 4300018036 & 478130 & 6674551 & 44,6 & 2,1 & - & 0,40 & 0,65 & 0,70 & 0,18 & $\operatorname{ArG}$ \\
\hline 4300018039 & 477403 & 6672700 & 24 & 1,14 & - & 0,80 & 0,50 & 0,90 & 0,36 & ArArg \\
\hline 4300018051 & 484078 & 6674554 & 88 & 13,7 & - & 0,60 & 0,59 & 0,80 & 0,28 & Gn \\
\hline 4300018057 & 482000 & 6675726 & 31 & 6 & - & 0,70 & 0,70 & 0,80 & 0,39 & Gn \\
\hline 4300018059 & 482221 & 6674378 & 36 & 3 & - & 0,70 & 0,68 & 0,90 & 0,43 & $\mathrm{Gn}$ \\
\hline 4300018066 & 478607 & 6677382 & 37 & 2 & - & 0,40 & 0,58 & 0,70 & 0,16 & $\operatorname{ArG}$ \\
\hline 4300018067 & 481632 & 6678745 & 55 & 22 & - & 0,70 & 0,68 & 0,70 & 0,33 & Gn \\
\hline 4300018070 & 479873 & 6672641 & 249 & 112 & - & 0,60 & 0,70 & 0,60 & 0,25 & $\mathrm{Gr}$ \\
\hline 4300018072 & 480801 & 6677029 & 73 & 31 & - & 0,70 & 0,70 & 0,70 & 0,34 & $\mathrm{Gr}$ \\
\hline 4300018073 & 478481 & 6674547 & 58 & 2,05 & - & 0,70 & 0,65 & 0,90 & 0,41 & $\mathrm{Gr}$ \\
\hline 4300018074 & 478015 & 6677706 & 28 & - & - & 0,80 & 0,67 & 0,70 & 0,38 & $\mathrm{Gr}$ \\
\hline 4300018078 & 479788 & 6672686 & 138 & 0 & - & 0,70 & 0,63 & 0,90 & 0,40 & $\mathrm{Gr}$ \\
\hline 4300018079 & 481636 & 6674070 & 37 & 11 & - & 0,80 & 0,67 & 0,80 & 0,43 & $\mathrm{Gr}$ \\
\hline 4300018085 & 479072 & 6675134 & 155 & 5 & - & 0,80 & 0,70 & 0,80 & 0,45 & $\mathrm{Gr}$ \\
\hline 4300018092 & 483655 & 6675512 & 185 & 6 & - & 0,70 & 0,69 & 0,80 & 0,39 & $\mathrm{Gr}$ \\
\hline 4300018095 & 482528 & 6678241 & 139 & 16 & - & 0,70 & 0,70 & 0,80 & 0,39 & $\mathrm{Ri}$ \\
\hline 4300018096 & 479128 & 6675910 & 70 & 4 & - & 0,70 & 0,70 & 0,90 & 0,44 & $\mathrm{Gr}$ \\
\hline 4300018097 & 482057 & 6677090 & 31 & 0,82 & - & 0,70 & 0,66 & 0,90 & 0,42 & $\mathrm{Gr}$ \\
\hline 4300018098 & 484098 & 6677647 & 29 & 0 & - & 0,70 & 0,59 & 0,90 & 0,37 & GnAlt \\
\hline 4300018101 & 480855 & 6678020 & 187 & 85,16 & - & 0,80 & 0,70 & 0,60 & 0,34 & Gn \\
\hline 4300018107 & 481794 & 6674984 & 160 & 0,5 & - & 0,70 & 0,70 & 0,90 & 0,44 & Gn \\
\hline
\end{tabular}




\begin{tabular}{|c|c|c|c|c|c|c|c|c|c|c|}
\hline Poço & UTM E & UTM N & $\begin{array}{c}\text { Entrada } \\
\text { d'água (m) }\end{array}$ & $\begin{array}{l}\mathrm{NE} \\
(\mathrm{m})\end{array}$ & $\begin{array}{l}\text { CT } \\
(\mathrm{m})\end{array}$ & G & 0 & D & GOD & $\begin{array}{l}\text { Litologia da zona } \\
\text { de captura }\end{array}$ \\
\hline 4300018108 & 481807 & 6675045 & 63 & 1 & - & 0,60 & 0,62 & 0,90 & 0,34 & $\mathrm{Gn}$ \\
\hline 4300018110 & 481359 & 6677548 & 12 & 5,2 & - & 0,70 & 0,60 & 0,80 & 0,34 & GrAlt \\
\hline 4300018120 & 480872 & 6682340 & 55 & 46,8 & - & 0,60 & 0,49 & 0,70 & 0,20 & $\mathrm{Gr}$ \\
\hline 4300018122 & 477754 & 6676587 & 33 & 2,28 & - & 0,70 & 0,61 & 0,90 & 0,39 & $\mathrm{Gr}$ \\
\hline
\end{tabular}

UTM: sistema de coordenadas Universal Transversa de Mercator (fuso 22S); NE: nível estático (m); CT: cota do terreno (m); SedAr: Sedimento arenoso; ArCong: Areia conglomerática; ArG: Areia grossa; ArM: areia média; SedAl: Sedimento aluvionar; GrIntemp: Granito Intemperizado; Gr: Granito; GrAlt: Granito alterado; ArArg: Areia argilosa; Gn: Gnaisse; GnAlt: Gnaisse alterado; Ri: Riolito

Figura 3 - Vulnerabilidade da Macrozona Cidade Radiocêntrica

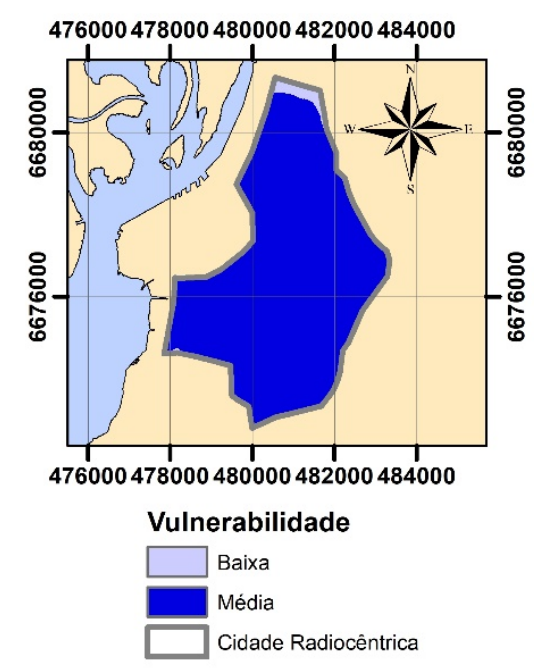

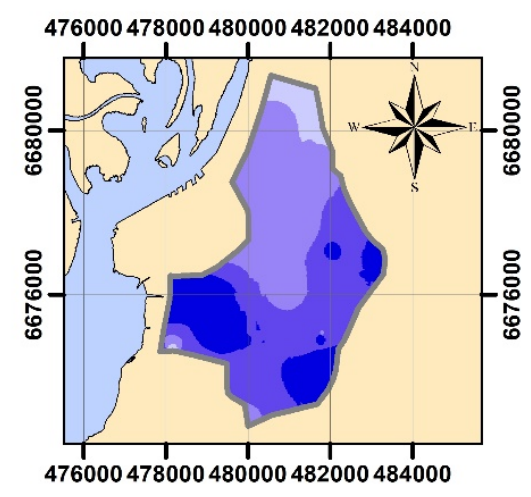

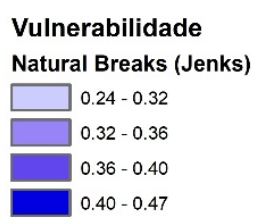

Datum: UTM SAD $6922 \mathrm{~S}$

\subsection{Zona de concentração das cargas contaminantes (ZCCC) na área de estudo}

Identificou-se a presença de 490 atividades potencialmente contaminantes localizadas na Cidade Radiocêntrica e em suas proximidades através do mapeamento de cemitérios e da análise dos registros da SMIC, nos quais constam indústrias, oficinas mecânicas e postos de abastecimento, conforme apresentado na Tabela 3. As tipologias das indústrias são colocadas de acordo com definição da SMIC. A maior parte das indústrias estão localizadas no norte da Cidade Radiocêntrica, os cemitérios estão concentrados mais ao sul, enquanto que os postos de abastecimento e as oficinas mecânicas se encontram distribuídos pela área de estudo.
Ressalta-se a menor quantidade de fontes potencialmente contaminantes localizadas na parte central da macrozona.

A delimitação da Zona de Concentração de Cargas Contaminantes e a interpolação do índice POSH das atividades é apresentada na Figura 4. Como os índices atribuídos às cargas contaminantes pontuais são discretos, adotou-se intervalos igualmente espaçados para a apresentação e interpretação dos valores interpolados (1 a 1,67: reduzido; 1,67 a 2,33: moderado; 2,33 a 3: elevado). Destaca-se que foi considerado o valor contínuo (pixel a pixel) do índice POSH interpolado para o posterior cálculo do perigo de contaminação 
Tabela 2 - Atividades potencialmente contaminantes na Cidade Radiocêntrica

\begin{tabular}{|c|c|c|c|}
\hline Atividade & Quantidade & Índice POSH & Raio de influência \\
\hline Oficinas mecânicas & 355 & 3 & $100 m$ \\
\hline Postos de abastecimento & 117 & 2 & $100 m$ \\
\hline Cemitérios & 4 & 1 & $200 m$ \\
\hline $\begin{array}{l}\text { Fabricação de elementos e pro- } \\
\text { dutos químicos }\end{array}$ & 1 & 3 & \multirow{6}{*}{$200 m$} \\
\hline $\begin{array}{l}\text { Fabricação de estruturas metáli- } \\
\text { cas }\end{array}$ & 1 & 3 & \\
\hline $\begin{array}{l}\text { Fabricação de outros artefatos } \\
\text { de metal }\end{array}$ & 2 & 3 & \\
\hline $\begin{array}{l}\text { Fabricação de produto farma- } \\
\text { cêutico e veterinário }\end{array}$ & 6 & 3 & \\
\hline $\begin{array}{l}\text { Fabricação de produtos farma- } \\
\text { cêuticos e hospitalares }\end{array}$ & 1 & 3 & \\
\hline $\begin{array}{l}\text { Fabricação de sabões, deter- } \\
\text { gentes e glicerina }\end{array}$ & 3 & 2 & \\
\hline
\end{tabular}

Figura 4 - Delimitação da Zona de Concentração das Cargas Contaminantes (ZCCC) e índice POSH interpolado

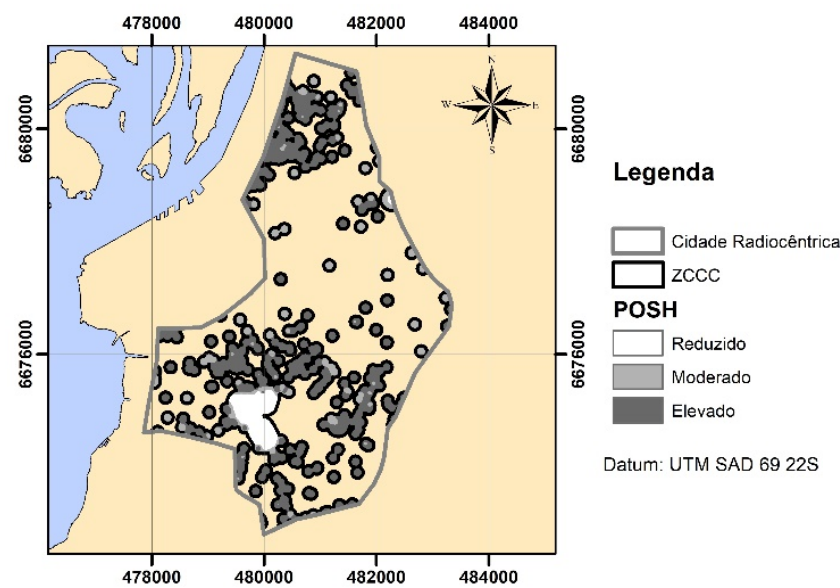

\begin{abstract}
A Zona de Concentração de Cargas Contaminantes possui uma área de $7,64 \mathrm{~km}^{2}$, estendendo-se sobre $32 \%$ da Cidade Radiocêntrica. Verifica-se que $75 \%$ da ZCCC possui um índice POSH elevado, $17 \%$ moderado e $8 \%$ reduzido, valores semelhantes aos verificados na proporção dos índices POSH das atividades analisadas pontualmente (conforme Tabela 3: $75 \%$ elevado, $24 \%$ moderado e $1 \%$ - correspondente aos cemitérios - reduzido). A diferença encontrada nos índices moderado e reduzido verificados pelas duas análises pode ser explicada pelo método de identificação dos cemitérios mapeamento a partir de imagens de satélite -, que possibilitou uma melhor delimitação desses locais, os quais possuem uma extensa área apesar de ocorrerem em pequena quantidade (apenas 04 unidades identificadas). Portanto, é possível afirmar que a ZCCC representa adequadamente as cargas contaminantes identificadas dentro da extensão proposta.
\end{abstract}

\subsection{Perigo de contaminação da água subterrânea}

O perigo de contaminação da água subterrânea da Cidade Radiocêntrica é apresentado na Figura 5. Constatou-se que as áreas com probabilidade de impactos negativos decorrentes da inserção de substâncias químicas indesejadas no recurso hídrico subterrâneo totalizaram 32\% do território, sendo que em $84 \%$ dessa região há um alto perigo de contaminação e, nos demais 16\%, um valor moderado. A região central da área de estudo apresenta uma menor probabilidade de disseminação de contaminantes na água subterrânea em função do pequeno número de atividades com potencial contaminador desenvolvidas na localidade. 
Figura 5 - Perigo de contaminação da água subterrânea na macrozona

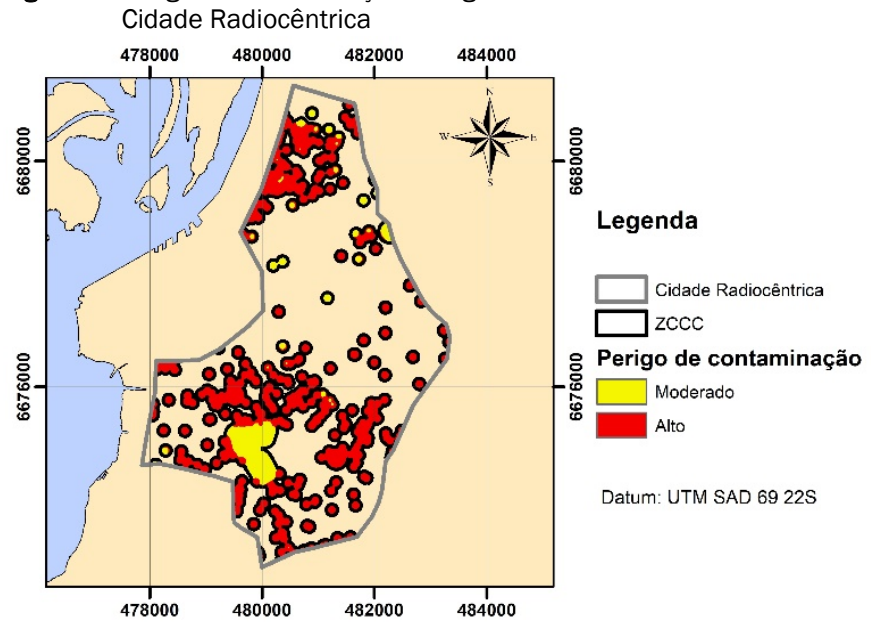

Observou-se que 9 dos 16 poços da Cidade Radiocêntrica (56\%) estão localizados em área com algum perigo de contaminação. Dentre os inseridos, 8 estão em região com alto perigo de contaminação (4300000124, 4300001446, 4300018034, 4300018057, 4300018079, 4300018096, 4300018107 e 4300018108$)$ e 1 em local de perigo moderado (4300018067).

Apesar de a Cidade Radiocêntrica constituir a área urbana mais estruturada de Porto Alegre, verificou-se que ela não apresenta em sua totalidade um perigo de contaminação à água subterrânea quando analisada a distribuição das cargas contaminantes pontuais. Desse modo, o detalhamento da espacialização dessas fontes possibilita uma melhor delimitação das áreas com maior probabilidade de contaminação, aprofundando as usuais análises espaciais realizadas por outros autores (e.g. MEIRA et al, 2014; PEREIRA JUNIOR et al, 2015). Assim, verifica-se que a Zona de Concentração de Cargas Contaminantes (ZCCC) constitui um possivel método para avaliação do perigo de contaminação oriundo da distribuição de cargas contaminantes pontuais em áreas urbanas.

\section{CONCLUSÕES}

O presente trabalho analisou o perigo de contaminação dos recursos hídricos subterrâneos a partir de uma proposta de integração das cargas contaminantes pontuais em área urbana. Escolheu-se a macrozona Cidade Radiocêntrica de Porto Alegre para a aplicação dessa espacialização, utilizando-se informações de vulnerabilidade e fontes potenciais de contaminação.

A região possui uma vulnerabilidade média na sua maior parte $(98 \%$ da área), contendo algumas áreas com valores classificados como baixos (2\%). Na área de estudo, foram identificadas 490 fontes pontuais potencialmente contaminantes compostas por postos de abastecimento, oficinas mecânicas, indústrias e cemitérios.

A incorporação dos empreendimentos elencados em uma Zona de Concentração de Cargas Contaminantes (ZCCC) correspondente a $32 \%$ da área de estudo, possuindo um índice POSH majoritariamente elevado (75\%), ao revelar a confluência das cargas contaminantes, auxiliou na identificação das áreas com perigo de contaminação, cujo valor varia entre moderado (16\%) e alto (84\%). Assim, conclui-se que a área urbana em sua integridade não necessariamente constitui um perigo de contaminação aos recursos hídricos subterrâneos.
O índice de perigo elaborado pode servir como complemento às ações de fiscalização e norteador de atividades de prevenção da contaminação da água subterrânea na macrozona Cidade Radiocêntrica do município de Porto Alegre. Trabalhos que complementem o cadastro de poços e verifiquem a ocorrência de empreendimentos potencialmente contaminantes irregulares aperfeiçoariam a composição desse complexo e dinâmico quadro de interações entre os recursos hídricos subterrâneos e o cenário urbano.

\section{REFERÊNCIAS}

ALBUQUERQUE, J. F. et al. Plano de desenvolvimento e proteção ambiental da área de afloramento do Sistema Aquífero Guarani no Estado de São Paulo: Proposta Preliminar. In: CONGRESSO BRASILEIRO DE ÁGUAS SUBTERRÂNEAS, 16. Anais... São Luiz, 2010.

ASSOCIAÇÃO BRASILEIRA DE NORMAS TÉCNICAS. ABNT NBR-15515-1: Passivo ambiental em solo e água subterrânea - Parte 1: Avaliação preliminar. Rio de Janeiro, 2007. $47 \mathrm{p}$

BRASIL. Ministério do Meio Ambiente. Agência Nacional de Águas. Panorama do enquadramento dos corpos d'água/ Panorama da qualidade das águas subterrâneas no Brasil. Brasília, 2007. 123 p. Disponível em: $<$ http://pnqa.ana.gov.br/Publicacao/PANORAMA_DO_ENQUADRAMENTO.p df>. Acesso em: 03 mai. 2016.

ALLER, L., BENNET, T., LEHR, J. H. e PETTY, R.J. DRASTIC: a standardized system for evaluating groundwater pollution potential using hydrogeologic settings, U.S. EPA Report 600/2-85/018.1987.

CUTRIM, A. O.; CAMPOS, J. E. G. Avaliação da vulnerabilidade e perigo à contaminação do aquífero Furnas na cidade de Rondonópolis (MT) com aplicação dos métodos GOD e POSH. Geociências UNESP, São Paulo, v. 29, n. 3, p. 401-411, 2010.

CPRM - Companhia de Pesquisa de Recursos Minerais. Projeto Plano Diretor de Mineração da Região Metropolitana de Porto Alegre - PDM (Mapa Geológico Integrado - escala 1:250.000). Porto Alegre, 2006.

DMAE. Plano Municipal de Saneamento Básico: Volume 1 - Diagnóstico. 2015. 232 p. Disponivel em: <http://lproweb.procempa.com.br/pmpa/pref poa/dmae/usu_doc/01_pmsb_diagnostico_web.pdf>. Acesso em: 04 abr. 2017.

FERON, G. L.; REGINATO, P. A. R. Avaliação da Vulnerabilidade de Aquíferos Localizados na Região Central de Canoas - RS. Águas Subterrâneas, v. 28, p. 1-13, 2014. 
FOSTER, S. S. D.; HIRATA, R. Groundwater pollution risk assessment: a methodology using available data. Lima: Pan American Health Organization/World Health Organization, 1988. 73 p.

FOSTER, S.; HIRATA, R.; GOMES, D.; D'ELIA, M.; PARIS, M. Proteção da Qualidade da Água Subterrânea: um guia para empresas de abastecimento de água, órgãos municipais e agências ambientais. Banco Mundial, Washington, D.C. 2006.

LIVINGSTONE, S., FRANZ, T., GUIGUER, N. Managing Ground-water Resources Using Wellhead Protection Programs. Geoscience Canada, v. 22, n.3, p. 121-128, $1995 . \quad$ Disponível em: <http://journals.hil.unb.ca/index.php/GC/article/view/3879/4393>. Acesso em: 26 mai. 2016.

MARTELLI, G. V.; DESCOVI FILHO, L. L. V.; DA SILVA, J. L. S. Determinação de Áreas de Risco Potencial de Contaminação das Águas Subterrâneas na Área Urbana de Cacequi/RS - Brasil. In: WORLD WATER CONGRESS, 14 Anais...Porto de Galinhas, 2011.

MEIRA, J. C. R.; DE-CAMPOS, A. B.; PEREIRA, L. C. Vulnerabilidade Natural e Perigo à Contaminação de Zona de Recarga do Aquífero Guarani. Águas Subterrâneas, v. 28, p. 31 - 46, 2014.

PEREIRA JÚNIOR, L. C.; SOARES, H. L. T.; DE CASTRO, S. S. Vulnerabilidade Natural e Risco de Contaminação do Aquífero Bauru no município de Rio Verde - GO. Águas Subterrâneas, v. 29, p. 129-145, 2015.
PINHEIRO, R. J. B.; RAUBER, A. C. C.; DA SILVA, J. L. S. Suscetibilidade à Contaminação dos Aquíferos no Município de Santa Maria - RS. In SEMINÁRIO DE ENGENHARIA GEOTÉCNICA DO RIO GRANDE DO SUL, 7. 2013. Anais.... Santa Maria, 2013.

PORTO ALEGRE. Lei $N^{\circ} 7.560$, de 22 de dezembro de 1994. Cria o Cadastro Municipal de Poços Tubulares Profundos.

PREFEITURA MUNICIPAL DE PORTO ALEGRE. Plano Diretor de Desenvolvimento Urbano Ambiental. Porto Alegre, 2010. Disponível em: <http://Iproweb.procempa.com.br/pmpa/prefpoa/spm/usu_doc/planodire tortexto.pdf>. Acesso em: 19 abr. 2016.

RODRIGUEZ, L.C.C.; RODRIGUES, L.S.; COLARES, E.R.; BENDATI, M.M.A. O geoprocessamento como ferramenta no Cadastro Municipal de Poços Tubulares Profundos no município de Porto Alegre (RS) In: SIMPÓSIO INTERNACIONAL DE QUALIDADE AMBIENTAL, 4., 2004, Porto Alegre (RS). Anais... Porto Alegre: ABES/RS, 2004.

STEMPVOORT, D.; EWERT, L.; WASSENAAR, L. Aquifer vulnerability index: a GIS-compatible method for groundwater vulnerability mapping. Canadian Water Resources Journal, v. 18, n. 1, p. 25-37, 1993.

TAVARES, P. R. L.; DE CASTRO, M. A. H.; DA COSTA, C. T. F. Mapeamento da vulnerabilidade à contaminação das águas subterrâneas localizadas na Bacia Sedimentar do Araripe, Estado do Ceará, Brasil. Rem: Rev. Esc. Minas, Ouro Preto, v. 62, n. 2, p. 227-236, 2009. 